\section{Estratégias de PROMOÇÃo PARA O COMÉRCIO EXTERIOR BRASILEIRO: O CASO DO SETOR TÊXTIL*}

Claudia Raphaeta Borges** Aquiles Elie Guimarães Kalatzis*** Paula Roberta Velho****

\section{Introdução}

As exportações brasileiras têm crescido de forma expressiva nos últimos anos, transformando-se em um dos motores do crescimento econômico. Papel especial é desempenhado pelo setor têxtil, atingindo a cifra de mais de 2 bilhões de dólares na pauta exportadora em 2004 e respondendo por cerca um milhão de empregos diretos e indiretos em empresas de capital majoritariamente nacional. Desse volume exportado, mais de $40 \%$ são concentrados nos mercados argentino e americano.

Este trabalho tem por objetivo identificar e apontar as principais estratégias de promoção do comércio exterior de forma geral e, em particular, para o setor têxtil. Primeiramente é analisado o desempenho do comércio exterior brasileiro frente ao comércio mundial, destacando a necessidade de expandir a sua participação para um valor superior aos atuais 1\%. Na seção 2 são apresentadas as estratégias de promoção do comércio exterior, seguidas das estratégias de promoção de exportação do setor têxtil. Por fim, nas considerações finais, são destacadas as necessidades da adoção de estratégias que levem à inovação tecnológica com o intuito de reduzir os custos de produção, melhorar a qualidade e, então, poder atingir novos mercados.

*Artigo apresentado para conclusão do Curso de Especialização em Comércio Exterior da UNIARA, em 2005, elaborado pela primeira autora sob orientação e co-orientação do segundo autor e da terceira autora.

**Graduada em Turismo e Especialista em Comércio Exterior pela UNIARA. E-mail: claudiaborges@lupo.com.br.

***Doutor em Economia pela FEA-USP - São Paulo. Professor do Departamento de Engenharia de Produção EESC-USP / São Carlos. E-mail: aquilies@prod.eesc.usp.br.

****Master of Science in Economics; Queen Mary and Westifield College; University of London. Londres, Inglaterra, 1990-1991. Docente do Departamento de Ciências da Administração e Tecnologia e Membro do Grupo de Pesquisa Multidisciplinar "Gestão das Organizações”, da UNIARA.E-mail: paulavelho@terra.com.br.
O comércio exterior brasileiro e o comércio mundial

As exportações desempenham um papel de grande importância no crescimento e desenvolvimento de uma nação, sobretudo para os países que apresentam grandes restrições externas, acentuadas pelo novo paradigma tecnológico e pelo processo de globalização. Nesse sentido, um desempenho mais dinâmico e diversificado na pauta exportadora brasileira torna-se de grande importância para a economia nacional. A conquista de novos mercados com uma pauta exportadora mais diversificada exige que esforços e estratégias na promoção das exportações sejam implementados.

Durante praticamente toda década de 70 e 80 a balança comercial obteve superavits, mas a partir de 1995 esse quadro mudou. A política comercial brasileira, no período, condicionou-se ao uso do câmbio como âncora nominal de preços, com inflações residuais que contribuíram para gerar elevados déficits em conta corrente. Em conseqüência, a desvalorização da moeda servia como estímulo para as exportações. Esse novo aspecto da economia trouxe um novo ambiente de mercado, mais aberto e competitivo, exigindo uma nova estratégia de comércio exterior.

Aumentar as exportações era o novo foco do país, dada a necessidade de divisas e de elevados saldos na balança comercial. Mudanças na área externa e interna foram tomadas com o intuito de reformular o conceito de comércio exterior.

Com a implementação do plano Real, em julho de 1994 que tinha por objetivo o controle do processo inflacionário que atingiu a taxa de $2.489 \%$ em 1993 , a balança comercial passa a apresentar saldos negativos. Um dos principais mecanismos de controle de inflação utilizado ficou conhecido como "Âncora Cambial”, que operava através de um regime de câmbio semi-fixo. Como conseqüência do novo regime de câmbio adotado, ocorre uma apreciação da moeda nacional, o que passa a comprometer a competitividade dos produtos nacionais exportáveis, acarretando déficits na balança comercial a partir de 1995.

Os saldos comerciais tornam-se positivos somente a partir de 2001, como conseqüência da desvalorização cambial ocorrida em 1999. Já em 2004, os resultados das exportações mostram um crescimento elevado, atingindo um valor próximo dos US\$ 100 bilhões, algo atípico na economia brasileira, e um recorde histórico. Vários são os motivos desse cenário favorável às exportações, como a diversificação dos produtos, abertura de novos mercados e aumento no número de empresas exportadoras. As exportações brasileiras nunca foram tão promissoras quanto na atualidade.

A Tabela 1 mostra um forte crescimento de 35,7 \% no superávit comercial do Brasil, para US\$ 33,693 bilhões. As exportações apresentaram um valor US\$ 96,475 bilhões frente a importações de US\$ 62,779 bilhões, crescendo 32\% em relação ao ano de 2003. Por outro lado, as importações aumentaram 30 \% com relação a 2003. 
Tabela 1. Evolução da Balança Comercial Brasileira 1995-2004 Em US\$ milhões FOB.

\begin{tabular}{|c|c|c|c|c|c|c|c|c|c|c|c|}
\hline Disc & 1995 & 1996 & 97 & 998 & $\mid 1999$ & 2000 & 2001 & 2002 & 2003 & 2004 & \begin{tabular}{|c|} 
Var. \\
$(\%)$ \\
$2004 / 03$
\end{tabular} \\
\hline XPORTACÃO & ,506 & 47,747 & 2,994 & 51,140 & 48,01 & 86 &, 22 & 362 & 73,084 & 6,475 & 32.0 \\
\hline & 969 & \begin{tabular}{|l|l|}
11,900 \\
\end{tabular} & 14,474 & \begin{tabular}{|l}
12,977 \\
\end{tabular} & \begin{tabular}{|l}
11,828 \\
\end{tabular} & \begin{tabular}{|l|}
12,566 \\
\end{tabular} & \begin{tabular}{|l|l}
15,342 \\
\end{tabular} & \begin{tabular}{|l|l}
16,952 \\
\end{tabular} & \begin{tabular}{|l}
21,179 \\
\end{tabular} & 8,518 & 34.7 \\
\hline Fit & \begin{tabular}{|l}
34,711 \\
\end{tabular} & \begin{tabular}{|l|}
35,026 \\
\end{tabular} & 37,672 & \begin{tabular}{|l}
37,507 \\
\end{tabular} & \begin{tabular}{|l|}
35,311 \\
\end{tabular} & \begin{tabular}{|l}
41,027 \\
\end{tabular} & \begin{tabular}{|l|}
41,144 \\
\end{tabular} & \begin{tabular}{|l}
41,965 \\
\end{tabular} & 0,597 & 88 & 31.2 \\
\hline & 9,146 & 8,613 & 8,478 & 8,120 & 7,982 & 99 & 8,244 & 8,964 & 10,943 & & \\
\hline & & 26 & 29,194 & $9,5,4$ & (27000 & & & & & & \\
\hline & 826 & 821 & 848 & 656 & 87 & \begin{tabular}{|r}
1,498 \\
\end{tabular} & 1,7 & 1,445 & 1,308 & 1,579 & 20.7 \\
\hline & 49,972 & 53, & 59,746 & 57,746 & 49,27 & 55 & & 47,240 & 48,291 & 02 & \\
\hline ns Inter. & 2,509 & 24,560 & 26,014 & 26, & 24,042 & & & & 25,828 & & \\
\hline & \begin{tabular}{|l}
10,916 \\
\end{tabular} & & 11,232 & & 7,418 & & & & 5,538 & 6 & \\
\hline & \begin{tabular}{|l}
5,319 \\
5,219
\end{tabular} & $\begin{array}{l}6,220 \\
6,20\end{array}$ & \begin{tabular}{|l}
11,252 \\
5,824
\end{tabular} & \begin{tabular}{|r|}
4,107 \\
\end{tabular} & $\begin{array}{l}4,+1057 \\
, 257\end{array}$ & $\begin{array}{l}, 0011 \\
6,357\end{array}$ & \begin{tabular}{|r|}
6,276 \\
\end{tabular} & $\begin{array}{l}, 3,240 \\
, 2\end{array}$ & 6, 6,570 & 88 & 56.6 \\
\hline & \begin{tabular}{|l|l}
11,328 \\
\end{tabular} & 12,753 & \begin{tabular}{|l}
16,676 \\
\end{tabular} & \begin{tabular}{|l|l}
16,098 \\
\end{tabular} & 13,555 & \begin{tabular}{|l|l}
13,602 \\
\end{tabular} & \begin{tabular}{|l}
14,80 \\
\end{tabular} & 11,6 & \begin{tabular}{|l}
10,348 \\
\end{tabular} & 12,126 & $17+2>$ \\
\hline & & & & -6006 & & \begin{tabular}{|l|l|}
-749 \\
\end{tabular} & 26 & & & 32606 & \\
\hline
\end{tabular}
Fonte: MICT/Secex.

A corrente de comércio somou US\$159,275 bilhões em 2004. Comparada aos US\$121,375 bilhões de 2003, apresenta expressivo crescimento de 31,2 \%, indicando novo patamar de comércio externo para o País.

Apesar do acelerado crescimento das exportações brasileiras nos últimos anos, ultrapassando a marca dos US\$ 100 bilhões, considerando os últimos dozes meses, de agosto de 2004 a julho de 2005, a participação nas exportações mundiais e a concentração em produtos de baixo valor agregado e de baixo dinamismo tecnológico são entraves que devem ser considerados. Isto pode ser notado quando se considera sua participação em relação às exportações mundiais, ainda muito baixa, isto é, representando cerca de apenas $1 \%$.

Os motivos apontados para o desempenho das exportações brasileiras, aquém da média mundial nos últimos anos, podem ser agrupados em dois tipos. Um primeiro destaca fatores macroeconômicos de competitividade, de cunho geral e sistêmico, tais como níveis desfavoráveis da taxa real efetiva de câmbio, inadequada infra-estrutura de apoio, insuficiência e custo de crédito. O segundo tipo refere-se à composição das exportações: a pauta está relativamente concentrada em produtos de baixo valor agregado e baixo dinamismo tecnológico, com crescimento de mercados externos abaixo da média mundial.

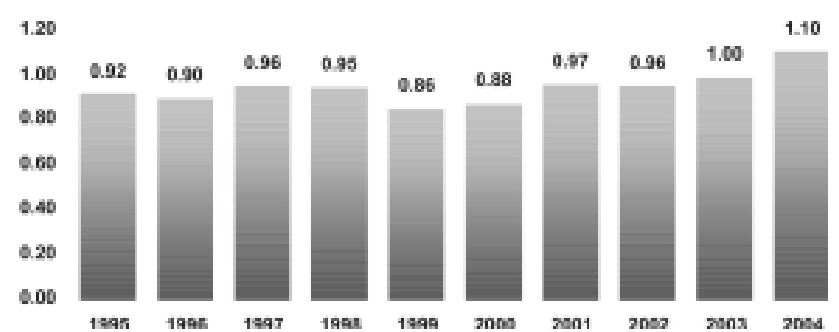

Figura 1. Participação das Exportações Brasileiras nas Exportações Mundiais. Fonte: MICT/Secex.
A Tabela 2 apresenta os principais grupos de produtos exportados, indicando que as exportações estão concentradas em uma pauta pouco diversificada e de baixo valor agregado. Nota-se, pela Tabela 2, que os produtos do complexo soja, carnes, minérios, metalúrgicos, papel e celulose e madeira representam grande parte das exportações, ou seja, cerca de $40 \%$ do total exportado.

Tabela 2. Principais produtos exportados em 2004.

\begin{tabular}{|c|c|c|c|}
\hline Principais Produtos & $\begin{array}{c}\text { Valor } \\
\text { US\$ } \\
\text { milhões }\end{array}$ & $\begin{array}{c}\Delta \% \\
2004 / 03\end{array}$ & Part \% \\
\hline Material de transporte & 16.042 & 50,9 & 16,6 \\
\hline Produtos metalúrgicos & 10.298 & 41,0 & 10,7 \\
\hline Complexo soja & 10.047 & 23,7 & 10,4 \\
\hline Carnes & 6.153 & 50,3 & 6,4 \\
\hline Qú́micos & 6.011 & 24,5 & 6,2 \\
\hline Petróleo e combustíveis & 5.732 & 16,9 & 5,9 \\
\hline Máqs. e equipamentos & 5.607 & 45,3 & 5,8 \\
\hline Minérios & 5.237 & 43,7 & 5,4 \\
\hline Calçados e couro & 3.337 & 19,1 & 3,5 \\
\hline Equip. elétricos & 3.122 & 4,2 & 3,2 \\
\hline Madeira & 3.044 & 46,3 & 3,2 \\
\hline Papel e celulose & 2.909 & 2,8 & 3,0 \\
\hline
\end{tabular}

Fonte: MICT/Secex

Sabe-se que no comércio internacional, 70 \% do fluxo estão concentrados em produtos industrializados de média e alta intensidade tecnológica. O Brasil vinha exportando somente $32 \%$ e importando os $70 \%$ dessa faixa de produtos, basicamente por falta de cultura exportadora, financiamento adequado e pelos tradicionais entraves burocráticos e tributários (MDIC, 2005).

Apesar do desafio para o avanço das exportações, com a substituição das importações de produtos industrializados de médio e alto valor agregado, passar pelo processo de inovação e renovação tecnológica para sucesso do novo modelo exportador brasileiro, também depende fortemente de estratégias de promoção de exportação para a conquista de novos mercados. Neste sentido, no próximo item pretende-se discutir aspectos relacionados à implementação de estratégias de promoção de comércio exterior.

\section{Estratégias de promoção de comércio exterior}

No contexto de globalização da economia, não somente as grandes empresas, mas também os pequenos negócios necessitam articular-se, buscar novas alternativas de comercialização, promover associações de interesse econômico, formar parcerias que garantam o sucesso dos seus investimentos e principalmente estar preparado para competir no mercado internacional.

O Brasil apresenta inúmeras limitações à competitividade das empresas 
e à sua participação no mercado externo. Diversos estudos têm apontado restrições e barreiras internas às exportações que afetam gravemente a capacidade competitiva das empresas brasileiras, tais como cultura exportadora e o custo-Brasil, decorrente da infra-estrutura e estrutura tributária.

Iniciando pelas questões tributárias, deve-se destacar que a base burocrática brasileira é antiga, alicerçada em impostos de importação, com práticas que foram modernizadas através de inúmeras ações corporativas. O foco principal da atividade fiscalizadora brasileira não está ligado ao produto ou à qualidade do bem, mas ao processo e a um conjunto de normas, instruções, portarias e regulamentos burocráticos para sua fabricação. Essa estrutura burocrática torna-se inadequada, uma vez que em um único processo produtivo há a intervenção de dezenas de entidades federais e estaduais. Como solução propõe-se a reformulação das funções fiscalizatórias e o estabelecimento de novos parâmetros administrativos que estejam de acordo com as existentes em outras economias abertas que têm obtido sucesso em sua inclusão ao mercado internacional

Quanto à infra-estrutura, os transportes são o principal entrave. A precariedade das ferrovias brasileiras, associada ao alto custo e prazo para sua remodelação, tornam o sistema rodoviário matriz do transporte brasileiro. A política utilizada no estabelecimento da cesta de tarifas de pedágios é incompatível com a relação custo-benefício da melhoria esperada nas condições de tráfego. É necessária a ampliação da malha básica e remoção dos gargalos existentes como também a redução dos fretes domésticos. Com relação aos portos, o modelo de recepção e despacho de cargas é obsoleto se comparado aos das grandes economias, que servem de centros de serviços de valor agregado e atuam como parceiros na montagem de serviços de logística internacional. Uma solução proposta por muitos especialistas na área seria a criação de uma única agência reguladora dos transportes atuando na resolução das ineficiências das infra-estruturas existentes e também das em expansão.

Por fim, é necessário criar uma cultura exportadora, através de uma forte política exportadora que simplifique os procedimentos, tornando-os ágeis e eficazes. Além das condições básicas, da adequação da infra-estrutura de transporte e regulação burocrático-fiscalizadora eficientes, adequadas e adaptadas para o novo ambiente, há a necessidade de ações específicas destinadas aos setores que demonstrem capacidade de reagir rapidamente mediante grandes oportunidades de expansão das vendas no mercado internacional.

Lima e Junior (2000) apontam que os principais entraves às condições de competitividade das empresas, principalmente as de pequeno e médio porte, estão relacionados a questões como: tamanho do mercado doméstico; maiores dificuldades para vender e estabelecer relações duradouras com compradores internacionais; dificuldades operacionais para realizar todas as transações envolvidas em uma operação de exportação; falta de acesso ao crédito; ausência de informações e de visibilidade das oportunidades existentes no mercado internacional, etc.. Assim, visando superar possíveis limitações, às possibilidades de crescimento das exportações brasileiras e aos próprios rumos do desenvolvimento econômico nacional, é necessário estabelecer um conjunto de alvos para políticas de promoção de exportações à semelhança do que fazem todos os principais países do mundo. Esse conjunto de alvos, além de receber atenção prioritária nas políticas gerais, especialmente acesso ao crédito e incentivo às exportações, deveria ser objeto de políticas específicas, visando à sua modernização produtiva, reorganização industrial, modernização tecnológica e outras políticas de natureza industrial.

Estratégias de promoção e um bom planejamento de marketing são imprescindíveis na abertura de novos mercados como também na disputa com a concorrência. Um bom planejamento estratégico de promoção e marketing internacional segundo Palácios e Sousa (2004), possui as seguintes fases:

Análise da situação - externa e interna: uma análise interna e externa da real situação da empresa deverá ser realizada com o intuito de verificar a possibilidade de serem obtidos recursos humanos, financeiros e tecnológicos suficientes para ingressar no exterior. E transformar esses recursos em capacidades que permitam suficiente competitividade nos novos mercados em que se objetiva operar. Trata-se do desenvolvimento de uma análise específica de recursos e capacidades de toda a empresa com o intuito de ingressar no mercado internacional.

Determinação dos objetivos: Os objetivos de internacionalização da empresa devem ser analisados de forma conjunta com os seus riscos. Isso significa que o mercado exterior deve ser considerado como somatória dentre os diversos portfólios de mercado de uma empresa e não apenas como uma possibilidade isoladamente. Somente dessa forma os objetivos propostos poderão ser alcançados com sucesso.

Investigação de mercados exteriores - seleção de mercados internacionais: seleção dos mercados alvos com que se objetiva trabalhar. Buscando melhores oportunidades que se adequem às necessidades e aos objetivos da empresa, pois os mercados mais atrativos nem sempre são os compatíveis com a realidade desta. Durante a investigação, os focos principais de analise devem ser: o estudo do ambiente do mercado desejado e sua dimensão e a identificação dos concorrentes e sua atuação. A execução desse processo deve-se concentrar no estudo dos diferentes segmentos que o mercado internacional tem a oferecer, que podem ser separados em três segmentos específicos: os universais, onde as necessidades e características são similares entre diferentes países; os diferentes, onde cada país apresenta características 
e comportamentos diferenciados, e os dos países homogêneos, que juntos representem características comuns para a venda de um determinado produto.

Plano estratégico internacional - estratégias de crescimento/ carteira de produtos: a partir dessa etapa o marketing internacional deve estar voltado, especificamente, para o mercado-alvo. Estratégias de crescimento, focando as características culturais do mercado-alvo devem ser elaboradas, tendo em vista as necessidades dos consumidores. A estratégia a ser utilizada e colocada em prática varia conforme o mercado em que se pretende atuar. Pode ser global, para países com pouca determinação de demanda ou específica, onde cada mercado será trabalhado de maneira única, levando-se em consideração as diferenças existentes entre os países.

Estratégias de entrada: Análise da capacidade de internacionalização da empresa e estudo das variedades técnicas recomendadas de comércio exterior para selecionar a melhor estratégia de entrada nos mercados em que se deseja atuar, atentando também para as peculiaridades e variedades culturais, existentes dentro de um mesmo país.

Marketing mix internacional: fusão dos quatro principais instrumentos de marketing conhecidos por 4Ps: produto (product), preço (price), distribuição (place), comunicação (promotion), a fim de se estabelecer uma completa estratégia de marketing, que melhor se adapte à entrada no mercado internacional.

Avaliação e controle: torna-se fundamental que a empresa avalie e controle todo o processo seguido para sua internacionalização e analise o seu desempenho empresarial mediante sua atuação nos distintos mercados. Esta avaliação é feita de maneira global, isto é, avaliando os resultados globais da empresa.

As fases acima citadas têm como objetivo orientar as empresas que desejam atuar no mercado internacional, abordando de maneira prática e eficiente as principais estratégias de marketing adotadas durante um processo de internacionalização.

Através desse sistema de plano de marketing internacional, permite-se não só conhecer melhor a empresa, mas também o ambiente em que pretende atuar além fronteiras, o que possibilitaria melhores condições de atingir o objetivo proposto no planejamento estratégico de promoção de marketing internacional.

Muitos aspectos de mercado são analisados para se desenvolver um bom planejamento de marketing. Os mais importantes são a análise da demanda e da concorrência e o estudo dos ambientes legal, econômico e cultural.

A análise da demanda consiste em obter a dimensão do mercado, objeto da investigação, observando toda sua estrutura com relação à concorrência, segmentação de produtos, comportamento do consumidor mediante suas necessidades e o que está sendo ofertado. Assim, pode-se determinar em que mercado atuar.
Analisar a concorrência implica em verificar pontos fortes e fracos, bem como as reações possíveis à inclusão no mercado; as condições de produção e introdução no mercado internacional, a receptividade desses produtos e a que preços são oferecidos.

Um estudo dos ambientes nos quais está inserida a empresa deve considerar o ambiente econômico - análise do PIB do país, inflação, taxas de juros, taxa de câmbio, renda per capita, financiamento ao crédito; o ambiente legal: eventuais barreiras alfandegárias com relação aos produtos a serem ofertados ou que possam servir de entraves; e o ambiente cultural: impactos culturais, religiosos, idioma, valores familiares, leis trabalhistas, etc.

Ainda segundo Palácios e Sousa (2004), a identificação e avaliação de mercados internacionais potenciais requer adoção de alguns critérios úteis, descritos no Quadro 1.

Quadro 1. Roteiro para avaliação de um mercado potencial

\begin{tabular}{|l|}
\hline 1. Regulamentações comerciais do próprio país \\
\hline - restrições no plano nacional; \\
- regulamentações em matéria de impostos e divisas; \\
- requisitos para a obtenção de licenças e outros documentos. \\
\hline 2. Acesso ao mercado \\
\hline - direitos aduaneiros (aplicados ao próprio país ou a terceiros); \\
- restrições em matéria de divisas; \\
- regulamentações sanitárias e de segurança; \\
- fatores políticos que influenciam o acesso. \\
\hline 3. Volume, estrutura e expansão do mercado \\
\hline - importações (volume, valor, procedência, tendências); \\
- consumo (volume, tendências, estrutura geográfica, demanda derivada, segmentação do \\
mercado); \\
- fatores que influenciam a demanda (econômicos, climáticos, geográficos, socioculturais). \\
\hline 4. Concorrência \\
\hline - produção no mercado interno, seu volume e crescimento; \\
- estrutura (identificação dos concorrentes mais importantes, cota de mercado, localização \\
dos estabelecimentos, capacidade, planejamento); \\
- envergadura das empresas, vantagens especiais; \\
- motivos de êxito; \\
- lacunas nas linhas de produtos; \\
- marcas de fábrica e patentes. \\
\hline 5. Estrutura de preços \\
\hline - preços que o consumidor pagará pelos produtos; \\
- margines comercias; \\
- custos de transporte; \\
- preços "normais de venda”. \\
\hline
\end{tabular}

Fonte: Palácios e Souza, 2004. 
Observa-se que os critérios propostos no Quadro 1 avaliam de forma específica o mercado potencial, apontando às empresas que objetivam atuar no mercado internacional. Os pontos chaves a serem analisados seriam: regulamentações, acessibilidade, o mercado como um todo, concorrência e estrutura de preços.

Considerando as estratégias propostas neste item e tendo como objetivo viabilizar e facilitar a atuação no mercado internacional das empresas exportadoras de forma geral, no próximo item procurar-se-á direcionar tais estratégias para o setor têxtil.

\section{O setor têxtil e o comércio exterior: Estratégias de exportação}

A indústria têxtil brasileira, por ter sido um dos primeiros ramos industriais a ser formado tem uma participação histórica e decisiva no processo de desenvolvimento industrial do país. Atualmente o Setor Têxtil é formado por cerca de 5.000 empresas, das quais apenas $11 \%$ são consideradas de grande porte e $21 \%$ de pequeno e médio porte. As microempresas, que atingem $68 \%$ do total das empresas do setor, representam a grande maioria do setor. Embora os dados sejam escassos, estima-se que $80 \%$ do total dessas empresas sejam de pequeno porte, sendo que 40 a 50\% trabalham informalmente, configurando a chamada economia informal.

No que concerne à propriedade do capital, o setor têxtil caracteriza-se por ser constituído por empresas de capital nacional, pois 91\% têm como proprietários brasileiros e apenas $9 \%$ são de capital estrangeiro.

O setor têxtil, bastante diversificado, compreende diferentes ramos de especialização: Fiação, Tecelagem, Malharia, Acabamento, Tricotagem, Artefatos de Passamanaria, Tecidos Elásticos, Fitas, Filós, Rendas, Bordados e Tecidos Especiais.

Para atender à demanda do mercado no que diz respeito a máquinas, seja para reposição ou expansão do setor, o Brasil desenvolveu uma indústria de máquinas, equipamentos e acessórios têxteis e de confecção, com mais de 60 anos de existência, operando com tecnologia própria ou procedente do exterior. Tem-se atraído, efetivamente, um grande número de fabricantes de máquinas têxteis para o Brasil. Alguns dos principais construtores de equipamentos do mundo encontram-se atuando no mercado brasileiro. Cerca de 120 fabricantes empregam 5.000 pessoas nesse setor.

No que tange aos recursos humanos, a indústria têxtil é o quinto maior empregador de mão-de-obra na indústria de transformação, sendo que este percentual sobe para $15 \%$ quando se agrega o setor de confecção.

O setor têxtil caracteriza-se por uma forte heterogeneidade estrutural, expressão das possibilidades de operação de plantas industriais com distintos níveis tecnológicos, bem como da natureza do processo produtivo.
Convém ressaltar que somente as grandes e médias empresas detêm o conhecimento tecnológico de todas as fases do processo produtivo, como por exemplo, o processo de melhora e enobrecimento de tecidos e malhas em que os micros e pequenos empresários não apresentam capacidade de investimento necessário para tais operações.

O setor estrutura-se com empresas espalhadas por todas as regiões do País, gerando milhões de empregos, sejam eles diretos na fase de produção fabril, ou indiretos, na produção de matérias-primas e vários outros insumos. Embora indefinido o número de trabalhadores diretamente agregados ao processo produtivo têxtil, estima-se em, aproximadamente, um milhão de pessoas. A Tabela 3 mostra a geração de postos de trabalho analisados mensalmente durante os anos de 2000 a 2004.

O aumento nos postos de trabalho que se observa, sobretudo nos anos de 2002 e 2004, deve-se ao fato de que grande parte das empresas do setor não possui grande avanço tecnológico, sendo intensivas em mão-de-obra. Por outro lado, houve também a pressão do governo na efetivação de funcionários, onde as pequenas e médias empresas ainda trabalhavam com a maior parte de sua mão-de-obra, sem registros.

Seu desempenho no comércio exterior, proporcionando uma geração líquida de divisas das mais significativas de todo o setor industrial, cerca de um bilhão de dólares anuais, realça ainda mais sua importância no cenário econômico nacional. A Tabela 4 mostra as exportações brasileiras de produtos têxteis no período de 1995 a 2004.

Tabela 3. Geração de postos de trabalho.

\begin{tabular}{|l|r|r|r|r|r|r|}
\hline \multirow{2}{*}{ Mes } & \multicolumn{7}{|c|}{ Ano } \\
\cline { 2 - 7 } & $\mathbf{2 0 0 0}$ & $\mathbf{2 0 0 1}$ & $\mathbf{2 0 0 2}$ & $\mathbf{2 0 0 3}$ & $\mathbf{2 0 0 4}$ & Média \\
\hline Janciro & 2.477 & 589 & 819 & -690 & 1.587 & 956 \\
\hline Fevereiro & 3.812 & 3.390 & 1.498 & -447 & 3.706 & 2.392 \\
\hline Março & 6.619 & 3.903 & 4.901 & 852 & 7.664 & 4.794 \\
\hline Abril & 8.908 & 5.747 & 5.449 & 2.887 & 7.935 & 6.185 \\
\hline Maio & 6.204 & 1.541 & 2.634 & 1.512 & 9.385 & 4.255 \\
\hline Junho & 1.613 & -2.343 & 2.343 & 2.281 & 7.572 & 2.293 \\
\hline Julho & 2.782 & -3.322 & -359 & -2.413 & 7.336 & 805 \\
\hline Agosto & 4.686 & 105 & 2.468 & 46 & 10.414 & 3.544 \\
\hline Setembro & 6.801 & 3.645 & 8.876 & 5.112 & 11.181 & 7.123 \\
\hline Outubro & 5.737 & 5.929 & 5.897 & 6.639 & 9.660 & 6.772 \\
\hline Novembro & 3.076 & 950 & 1.733 & 2.009 & 1.115 & 2.443 \\
\hline Dezembro & 12.103 & 13.359 & 13.728 & 16.111 & 15.260 & 14.172 \\
\hline Soma & $\mathbf{4 0 . 6 4 2}$ & $\mathbf{6 . 7 7 5}$ & $\mathbf{2 2 . 5 3 1}$ & $\mathbf{1 . 3 7 7}$ & $\mathbf{6 5 . 6 2 5}$ & \\
\hline
\end{tabular}

Fonte: MTE/CAGED

Nota-se, pela Tabela 4, que houve uma redução nas exportações de produtos têxteis de 1995 a 1999. Somente a partir de 2000 é que as exportações 
começam a crescer no período analisado, proporcionando a partir de 2001 um superávit na balança comercial do setor.

Tabela 4. Balança comercial têxtil e de confecções- 1995 a 2004 (em US\$1.000.000)

\begin{tabular}{|r|r|r|r|}
\hline Ano & Exportação & Importação & Saldo \\
\hline 1995 & 1.441 & 2.286 & $(845)$ \\
\hline 1996 & 1.292 & 2.310 & $(1.018)$ \\
\hline 1997 & 1.267 & 2.416 & $(1.149)$ \\
\hline 1998 & 1.113 & 1.923 & $(810)$ \\
\hline 1999 & 1.010 & 1.443 & $(433)$ \\
\hline 2000 & 1.222 & 1.606 & $(384)$ \\
\hline 2001 & 1.306 & 1.233 & 73 \\
\hline 2002 & 1.185 & 1.033 & 152 \\
\hline 2003 & 1.656 & 1.061 & 595 \\
\hline 2004 & 2.079 & 1.422 & 657 \\
\hline
\end{tabular}

Fonte: MDIC - Alice Web. Elaboração: ABIT.

O desempenho no comércio exterior brasileiro de produtos têxteis tem aumentado substancialmente nos últimos anos, mesmo considerando que compete com países de maior tradição, principalmente a China, que neste ramo tornouse um dos maiores concorrentes de todos os tempos. Pode se observar, pela Tabela 5, que dos dez primeiros destinos das exportações no setor têxtil, cinco são para países da América do Sul. Esses dez países respondem por mais de $70 \%$ do total das exportações têxteis. A pauta exportadora do setor têxtil apresenta também uma forte concentração em apenas dois países, Argentina e EUA, representando mais de $40 \%$ do total exportado.

Apesar do bom desempenho exportador brasileiro do setor têxtil nos últimos anos, o Brasil enfrenta uma forte concorrência no mercado internacional, de países como Paquistão, China e até dos “tigres asiáticos”.

Tabela 5. Origem das importações e destino das exportações de têxteis 2001.

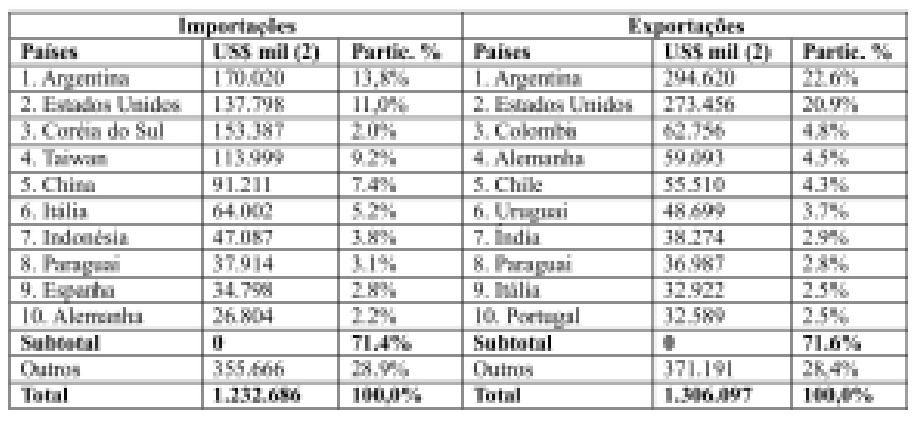

Fonte: MDIC.
Dentre os mecanismos de concorrência mais adotados pelas empresas, destacam-se as estratégias de comercialização (exportação, regionalização, especialização) e a integração vertical das atividades, ficando em segundo plano a adoção agressiva de inovações técnicas. Os baixos gastos com $\mathrm{P} \& \mathrm{D}$ realizados pelo setor fazem com que as inovações tecnológicas na área têxtil sejam de naturezas incrementais e geradas predominantemente em outros setores industriais. Como exemplo, cita-se o uso da microeletrônica que propicia um aumento no controle sobre o processo de produção, devido a sua maior capacidade de gerar, armazenar e analisar informações.

Recente pesquisa revela que, para as empresas, a difusão de tecnologia no setor esbarra em elementos como alto custo, dificuldades de importação de equipamentos e peças de reposição e oferta limitada de equipamentos no mercado interno. Essas barreiras fazem com que novas tecnologias e a tecnologia convencional compartilhem os espaços de produção.

Vários estudos têm apontado como tendência ou grandes necessidades do setor a renovação do parque fabril, para diminuir a obsolescência das máquinas e equipamentos. As ações, no entanto, apontam pela aquisição de novos equipamentos, que geralmente não incorporam avanços tecnológicos. Incrementos nas exportações passariam obrigatoriamente pela renovação do capital com a adoção de novas tecnologias.

Além da questão tecnológica, outro fator que interfere nas exportações é a situação econômica do país. Oscilações no poder aquisitivo geram picos de demanda intercalados por recessões e dificultam o planejamento da produção e da comercialização dos produtos do setor.

Outro entrave é a falta de padronização, tal como a ausência de normas exigidas pela $\mathrm{ABNT}$ que forneça dimensões e padrões para vestuário. A ausência de tais normas dificulta a padronização e satisfação do cliente.

Devido à dinâmica de funcionamento do setor têxtil é quase impossível separar a observação dos setores entrantes da própria concorrência interna. Mais de $50 \%$ da produção têxtil no Brasil podem ser caracterizados como informal e predominam nas etapas do corte e confecção, nas quais as grandes organizações, médias e pequenas empresas dividem espaço com um grande número de micro-empresas, geralmente informais. Nas etapas de fiação, tecelagem, malharia e acabamento predominam as grandes e médias empresas, diminuindo o grau de informalidade. O mesmo ocorre no desenvolvimento de novos produtos. As tarefas desenvolvidas nesta etapa requerem o uso de mãode-obra com alto grau de especialização e geram alto custo, dificultado a ação de micro e de pequenas empresas.

As dinâmicas e flutuações da moda a que o produto de vestuário é submetido somadas à sua sazonalidade fazem com que as empresas mais ágeis, 
normalmente as informais, levem vantagens competitivas. A vulnerabilidade das grandes empresas reside exatamente no seu porte, sinônimo de pouca flexibilidade, perdendo em agilidade para pequenas e micros. Apenas o maciço investimento em tecnologia e a administração da concorrência podem trazer a agilidade que as empresas precisam, tornando-as definitivamente competitivas.

\section{Considerações finais}

O presente trabalho destacou a importância das exportações para economias como a brasileira, tendo como foco o setor têxtil. Procurou-se analisar as estratégias de promoção de exportação adotadas pelas empresas do setor e observou-se que parte significativa do desempenho atual do setor, no cenário externo, deve-se às estratégias de comercialização, centradas na regionalização e especialização, o que explica o fato de cerca de $50 \%$ das exportações se direcionarem para a Argentina e os Estados Unidos.

A entrada da China e da Índia no mercado tem trazido ameaças e dado sinais para a indústria têxtil brasileira, considerada até pouco tempo competitiva no segmento de tecidos naturais e confecção. O futuro do setor dependerá de suavização das barreiras internas como infra-estrutura, carga tributária e cultura exportadora. Do ponto de vista empresarial, as firmas poderão identificar, como parte das estratégias de internacionalização, oportunidades criadas pela guerra do Iraque, em novos mercados como do Oriente Médio, onde a marca Brasil continua forte.

A conquista de mercados mais exigentes e uma ampla diversificação de mercados, no entanto, dependerão de investimentos em tecnologia que possam trazer inovações para o setor, de forma a permitir redução nos custos de produção e melhorias na qualidade.

\section{Referências:}

ABIT. ASSOCIAÇÃO BRASILEIRA da INDÚSTRIA TÊXTIL e de CONFECÇÃO. Disponível em: http://www.abit.org.br. Acesso em: jun. 2005.

ALÉM, A.C. Promoção às exportações: o que tem sido feito nos países da OCDE?. Revista do BNDES, Rio de Janeiro, v.7, n.14, p.229-252, 2000.

GREMAUD, A.P. et al. Economia brasileira contemporânea. 4.ed. São Paulo: Atlas, 2002.

LIMA, E.T. et al. Ações para acelerar a expansão das exportações.

Revista do BNDES, Rio de Janeiro, v.7, n.14, p.253-272, 2000.
MARTINELLI, D.P. et al. Negociação internacional. São Paulo: Atlas, 2004.

MIDC - MINISTÉRIO Do DESENVOLVIMENTO, INDÚSTRIA e COMÉRCIO EXTERIOR disponível em: http://

www.desenvolvimento.gov.br. Acesso em: jul. 2005

\section{PALACIOS, T.M.B.; SOUZA, J. Estratégias de marketing}

internacional. São Paulo: Atlas, 2004.

RICHERS, R. Surfando as ondas do mercado. 5.ed. São Paulo: RR\&CA 1997.

\section{Resumo:}

O comércio exterior brasileiro vem crescendo continuamente. Sua participação no comércio mundial, no entanto, não ultrapassa 1,1 \%. Barreiras internas de ordem estrutural, política, econômica e cultural por um lado, associadas à baixa cultura exportadora por outro, explicam parte de tal desempenho. Este trabalho procurou identificar as principais estratégias de promoção aplicadas ao comércio exterior e, em especial ao setor têxtil. Observou-se que o setor têxtil, embora tenha participação expressiva no grupo de manufaturados da pauta exportadora brasileira, atinge mercados restritos, como conseqüência das estratégias adotadas que têm como foco a comercialização e verticalização, em vez da tecnologia.

\section{Palavras-chave:}

Comércio Exterior, Setor Têxtil, Promoção de Exportação, Estratégias de Internacionalização. 